Journal of Patient-Centered

\title{
Partnering to Improve Care: Highlights From the 21st Annual Conference of the HMO Research Network
}

Michael K. Gould

Follow this and additional works at: https://aah.org/jpcrr

Part of the Medical Education Commons, and the Public Health Commons

\section{Recommended Citation}

Gould MK. Partnering to improve care: highlights from the 21st annual conference of the HMO Research Network. J Patient Cent Res Rev. 2015;2:75-77. doi: 10.17294/2330-0698.1200

Published quarterly by Midwest-based health system Advocate Aurora Health and indexed in PubMed Central, the Journal of Patient-Centered Research and Reviews (JPCRR) is an open access, peer-reviewed medical journal focused on disseminating scholarly works devoted to improving patient-centered care practices, health outcomes, and the patient experience. 


\title{
Partnering to Improve Care: Highlights From the $21^{\text {st }}$ Annual Conference of the HMO Research Network
}

\author{
Michael K. Gould, MD, MS \\ Department of Research and Evaluation, Kaiser Permanente Southern California, Pasadena, CA
}

\begin{abstract}
Almost 400 members and guests of the HMO Research Network (HMORN) met in Long Beach, California, March 11-13, 2015, for the Network's 21 ${ }^{\text {st }}$ Annual Conference, with the Kaiser Permanente Southern California Department of Research and Evaluation serving as the host site. Attendees from more than 25 different health care organizations participated in the conference, enjoying both the scientific exchange and the gorgeous views of the waterfront from the Hyatt Regency Hotel and Long Beach Convention Center. The conference theme, "Care Improvement Research: Partnering With Patients, Providers and Operational Leaders," was explored in panel discussions, concurrent sessions, poster presentations and ancillary meetings.
\end{abstract}

\section{Plenary Sessions}

In the first plenary session on Day 1, a distinguished panel of experts discussed "Research-Operations Partnerships to Improve Care." Panel members included:

- Jonathan Darer, MD, MPH, director of Institute for Advanced Application's Center for Clinical Innovation and chief innovation officer for the Division of Clinical Innovation, both of Geisinger Health System (Danville, PA);

- Robert Reid, $\mathrm{MD}, \mathrm{PhD}$, senior investigator from the Group Health Research Institute and medical director for Research Translation, Group Health Cooperative (Seattle, WA);

- Nirav Shah, MD, MPH, senior vice president and chief operating officer for Clinical Operations, Kaiser Permanente Southern California (Pasadena, CA); and - Leif Solberg, MD, associate medical director of HealthPartners Medical Group and clinical director of Care Improvement Research, HealthPartners Research Foundation (Bloomington, MN).

Correspondence: Michael K. Gould, MD, MS, 100 South Los Robles Ave, Suite 304, Pasadena, CA, 91101, T: 626-564-3926, Email: Michael.k.gould@kp.org
Each panel member described how he played a role in his organization that spanned research and clinical operations, summarizing recent successes and challenges in developing sustainable partnerships to improve patient-centered care. Among other insights, Dr. Darer highlighted infrastructure development and analytics as critical components of innovation, while Dr. Reid emphasized the importance of building relationships and codifying plans for improvement activities under a formal memorandum of understanding. Dr. Shah discussed how standardization of processes was critical to success, as was the need to design interventions that are amenable to scale up and spread. Dr. Solberg spoke about his experiences with the Institute for Clinical Systems Improvement, a nonprofit consortium of approximately 50 medical groups representing 8,000 physicians in Minnesota, reminding attendees that sometimes the most valuable learning opportunities arise from projects that fail.

On Day 2, the plenary session was a panel discussion of "Funding Opportunities and Priorities in Delivery System Science, Comparative Effectiveness Research and Implementation Science," which featured an impressive group of speakers from the National Institutes of Health and the Patient-Centered Outcomes Research Institute (PCORI, Washington, DC):

- Steven B. Clauser, PhD, MPA, program director of Improving Healthcare Systems, PCORI;

- Ann M. Geiger, MPH, PhD, acting associate director of Applied Research Program, Division of Cancer Control and Population Sciences (DCCPS), National Cancer Institute (Washington, DC); and

- David A. Chambers, DPhil, deputy director of Implementation Science, DCCPS, National Cancer Institute.

During this session, Dr. Clauser provided an introduction to PCORI and described its evolving funding portfolio in comparative effectiveness 
research and delivery system science, including a new program in pragmatic trials, as well as opportunities for Network members to respond to PCORI's broad and targeted funding announcements. Dr. Geiger gave an overview of reorganization efforts in the DCCPS and described recent funding announcements, including calls for studies of multilevel interventions in cancer care delivery and studies of survivorship care planning efficacy and impact. Dr. Chambers closed the session by introducing the field of implementation science, and by summarizing current training opportunities, resources and funding announcements in dissemination and implementation research.

\section{Awards and Other Special Presentations}

Midday sessions over lunch included the presentation of Early Career Investigator awards on Day 1, an inspiring State of the Network address on Day 2 by Jerry Gurwitz, MD, chair of the HMORN Governing Board, and a presentation on Day 3 from Dr. Clauser and Sarah Greene, MPH, about how to increase the odds of receiving funding by PCORI. Early Career Award recipients included second runner-up Nirupa Ghai, $\mathrm{PhD}$, MPH, from Kaiser Permanente Southern California, for her paper entitled "Disparities in Colorectal Cancer Screening Rates Among Asian Subgroups in a Large Managed Care Organization;" first runner-up Eva Chang, $\mathrm{PhD}, \mathrm{MPH}$, from Group Health Research Institute, for her paper "Reductions in Medical Resource Use Among Primary Care Physicians Following the Adoption of Personalized, Transparent Reporting;" and first-place winner Erin Hahn, PhD, MPH, from Kaiser Permanente Southern California, for her paper "Use of Low-Value Surveillance Services for Early Stage Breast Cancer Survivors." The very high quality of these abstracts and presentations bodes well for the future of the Network, and is a testament to the opportunities that the Network provides for junior investigators.

In the State of the Network presentation, Dr. Gurwitz summarized the recent accomplishments of the Network, thanked outgoing Governing Board Chair John Steiner, MD, MPH, for his exemplary service, and welcomed the Network's newest member, Catholic Healthcare Initiatives (CHI) and the CHI Institute for Research and Innovation (CIRI), Englewood, CO. CIRI will be represented on the HMORN Governing Board by Lela L. McFarland, MS, associate director of Data Management. Ms. McFarland and colleagues have already begun to contribute to the Network scientifically by presenting several posters at the conference describing ongoing work at CIRI. Dr. Gurwitz also led a town hall discussion of a name change for the Network, prompted by a Governing Board initiative to redefine the HMORN brand to be more up to date and relevant to the larger societal conversation about the role of health systems in health care reform. Shortly after the conference, the Governing Board voted in favor of changing the name to the "Health Care Systems Research Network." Following a year-long transition period, the Network will adopt the new name in May 2016.

Awards for "Paper of the Year" and "Biggest Reject" were presented during the opening night reception at the spectacular Aquarium of the Pacific in Long Beach. As attendees enjoyed the displays of sea otters, jellies, rays and other amazing underwater creatures, Biggest Reject awards were presented with great fanfare for the most begrudging acceptance, the greatest number of rejections and the quickest rejection of a paper. Without going into the painful details, it suffices to say that this group of awardees has set a very high bar for future "rejects" to match.

On a more serious note, Paper of the Year awards were presented to second runner-up Jeanette Waxmonsky, $\mathrm{PhD}$, from the University of Colorado (Boulder, CO), for her paper entitled "Cluster Randomized Trial of Enhanced Versus Standard Implementation Strategy to Improve Collaborative Care Uptake and PatientLevel Utilization Outcomes;" first runner-up Richard Meenan, $\mathrm{PhD}$, from Kaiser Permanente Northwest (Portland, OR), for his paper "An Economic Evaluation of Colorectal Cancer Screening in Primary Care Practice," and first-place winner Mary Helen Black, $\mathrm{PhD}$, MS, from Kaiser Permanente Southern California, for her paper "Evaluation of Knee Arthroscopy as a Low-Value Intervention for Treatment of Meniscal Damage in Patients With Osteoarthritis." In addition to the rigor and importance of the work, these abstracts demonstrate the tremendous diversity of methods and topics of interest to members of the Network.

In another conference highlight, Sascha Dublin, MD, $\mathrm{PhD}$, of Group Health Research Institute, and Dr. Black 
led a well-attended investigator development session that focused on working with funding agencies and building relationships with project officers. The preliminary feedback about this session was overwhelmingly positive, and plans are already underway to make this a regular feature of the annual conference.

\section{Concurrent Abstract and Poster Sessions}

This diversity was similarly reflected in the concurrent abstract and poster sessions. Concurrent sessions covered a wide spectrum of clinical content areas such as cancer, mental and behavioral health and geriatrics, as well as topical themes in care improvement research, health informatics, health economics, the Affordable Care Act, and patient and stakeholder engagement (PSE). The PSE session was enhanced by presentations from a patient stakeholder and from PCORI staff, who provided information about best practices for PSE from their research portfolio. The health informatics session benefited from an invited presentation by Alison Rein, MS, who represented the Evidence, Data \& Methods forum, an Agency for Healthcare Research and Quality-funded initiative that aims to advance the national dialogue on the use of electronic health data for research and quality improvement.

For the first time at the conference, attendees participated in two Poster Discussion sessions, a new format for abstract presentations. Sessions on Care Improvement Research and Cancer Care Improvement were well attended and succeeded in increasing interactions between presenters and audience members. In these sessions, 30 minutes of unopposed viewing of posters was followed by 60 minutes of moderated discussion that compared and contrasted posters thematically. At one of the sessions, discussion continued for almost half an hour after the session had officially ended.

Last but not least, more than 80 additional abstracts were presented at two traditional poster sessions. As always, the breadth of topics reflected the tremendous diversity of the Network and the opportunities for scientific exchange were abundant.

\section{Summary}

In retrospect, the Network's $21^{\text {st }}$ Annual Conference was a great success. The venue was outstanding, the opening night reception at the Aquarium was spectacular, the scientific sessions ran smoothly, and the science was impressive. Special thanks are in order for Conference Manager Michael Easterling and the members of the Scientific Planning Committee, too numerous to mention here. We are already looking forward to the $22^{\text {nd }}$ Annual Conference next May in Atlanta, Georgia, to be sponsored jointly by the Marshfield Clinic Research Foundation (Marshfield, WI) and the Henry Ford Health System (Detroit, MI). Once again, it will be a great opportunity to interact with friends and colleagues and set the course for the future of the HMO Research Network (soon to be known as the Health Care Systems Research Network). Whatever the name, the primary strength of the Network is its membership, a group of amazingly bright and collegial researchers who are partnering with patients, providers and operational leaders to help shape the future of health care. 